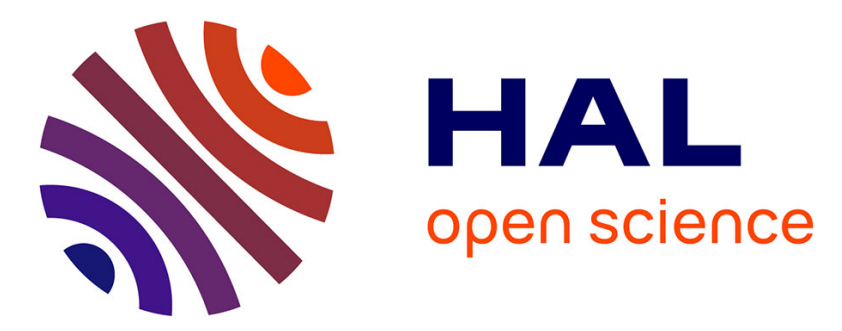

\title{
Revising the definition of research and development in the light of the specificities of services
}

\author{
Faridah Djellal, Dominique Francoz, Camal Gallouj, Faïz Gallouj, Yves
}

Jacquin

\section{- To cite this version:}

Faridah Djellal, Dominique Francoz, Camal Gallouj, Faïz Gallouj, Yves Jacquin. Revising the definition of research and development in the light of the specificities of services. Peace Economics, Peace Science and Public Policy, 2003, 30 (6), pp.415-429. halshs-01133147

\section{HAL Id: halshs-01133147 https://shs.hal.science/halshs-01133147}

Submitted on 18 Mar 2015

HAL is a multi-disciplinary open access archive for the deposit and dissemination of scientific research documents, whether they are published or not. The documents may come from teaching and research institutions in France or abroad, or from public or private research centers.
L'archive ouverte pluridisciplinaire HAL, est destinée au dépôt et à la diffusion de documents scientifiques de niveau recherche, publiés ou non, émanant des établissements d'enseignement et de recherche français ou étrangers, des laboratoires publics ou privés. 
(Published in Science and Public Policy: DJELlal F., FRANCOZ D., GALLOUJ C., GALLOUJ F., JACQUIN Y. (2003), Revising the definition of research and development in the light of the specificities of services, Science and Public Policy, 30/6, p. 415-429.)

\title{
Revising the definition of research and development in the light of the specificities of services ${ }^{1}$
}

\author{
Faridah Djellal*, Dominique Francoz**, Camal Gallouj*, \\ Faïz Gallouj*, Yves Jacquin**
}

Abstract:

Research and Development $(R \& D)$ is underestimated in services. This article combines deductive and inductive approaches in order to formulate a new definition of $R \& D$. However, the proposed revision does not fundamentally alter the structure of the current definition. The OECD definition is only marginally amended by making explicit certain implicit or insufficiently highlighted characteristics, in particular the importance of the social sciences and humanities and of design and development or organisational engineering, the composite nature of projects, etc. Our objective, indeed, is to attain a certain 'psychological' threshold that would mark our emancipation from the inertia of the still dominant industrialist and technologist approaches.

As William Baumol (2002) rightly points out in a provocatively titled paper ('Services as leaders and the leader of services'), not only is research and development a service activity but it also, and most importantly, occupies a privileged position among such activities. However, despite this commonality, and despite R\&D's strategic importance,

\footnotetext{
*Clersé-IFRESI, University of Lille1, Faculty of Economics and Sociology

**Ministry of National Education, Ministry of Research, Department of Programming and Development.

${ }^{1}$ We are indebted to the participants at the RESER's $11^{\text {th }}$ international conference, held in Grenoble on the $25^{\text {th }}$ and $26^{\text {th }}$ October 2001, for their comments, and in particular to Françoise Warrant, who sent us an extensive set of written comments that helped to enrich this article in a number of ways.
} 
service firms and service industries seem to make only a modest contribution to the R\&D effort, at least compared with those they make to employment and national wealth.

The aim of this article is to discuss this paradox and to show that, in reality, service firms' R\&D effort is often underestimated or even unrecognised. In our view, the explanation for this lies in the inability of the definitions and indicators of $R \& D$ to take account of certain specificities of the 'systematic creation of new knowledge' in services.

In other words, the indicators used by national statistical institutes, which draw on the directives contained in the various editions of the OECD's Frascati Manual, continue to convey an industrialist and technologist concept of R\&D and, more generally, of knowledge, that in our view considerably reduces the scope of activities leading to the 'creation of new knowledge', particularly in service industries. This prevailing image of R\&D very often leads service firms (including the largest ones) to feel uninvolved in such activities, whereas in fact they are engaged in high-level thinking about their 'products' or services, thinking that is entrusted to personnel with very high levels of expertise.

The emphasis put on the Manual and its success have several possible explanations. First of all, on a concrete side, R-D was a good indicator of innovativeness at both micro and macro levels. Its likely restrictive scope didn't matter as far as it was devoted to comparisions between firms, sectors or nations. On the theoretical side, the Manual was the expression of the old linear model of innovation in which R-D, production and marketing were separate and specialised activities.

The paper is based methodologically on a re-reading of the various versions of the Frascati manual and, above all, on a large-scale empirical investigation (with some fifty interviews forming the basis for thirty case studies of companies carrying out $R \& D$, compiling a register of several hundreds of research topics and itemising some fifty projects involving R\&D or comparable activities) in various service industries, including banking, insurance, postal services, large-scale food and non-food retailing, tourism, transport, cleaning, consultancy, hotels and mail order.

The paper is divided into six sections. 
The first section is given over to a presentation of the traditional definition of R\&D. The aim here is to analyse the principles on which the Frascati Manual's definition is based while at the same time outlining their theoretical foundations and the various stages in the process by which the definition was constructed.

The second section is given over to the (analytical) specificities of services. It is followed by a comparison with the fundamental principles of the traditional definition. This comparison is conducted at several levels: that of the general definition of R\&D (section 3 ), that of more specific problems concerning the boundary between R\&D and certain related activities (section 4) and that of the organisation of R\&D and of the actors involved (section 5). In this way, several analytical difficulties are identified which, to varying extents depending on the type of service activity in question, reflect the limits of the official concept of R\&D.

In the final section, we propose a number of amendments that make it possible to retain the structure of the current general definition of R\&D while at the same time taking account of the specificity of services.

\section{R\&D in the traditional sense: the main principles of the Frascati manual}

The universal point of reference when it comes to the definition of R\&D is the OECD Frascati Manual. The first edition of this manual was published in 1963. Since then, various international institutions, particularly the OECD itself, have sought to enhance the manual in various ways. Firstly, there has been a series of revisions of the original text (four in total' ${ }^{2}$; the 1993 edition is therefore the fifth edition of the Manual), which draw essentially on the results and assessments produced by various national surveys. Secondly, there has been a series of external enhancements, since it soon became clear that the notion of R\&D could not adequately account for total scientific and technological output. Thus other sets of definitions and indicators were used to supplement the Frascati Manual, in particular the Oslo Manual (OECD, 1970), which was given over to (technological) innovation, the Canberra Manual (OECD, 1995), which focused on the human resources allocated to science and technology, the patents manual (OECD, 1994) and the TBP manual, which was given over to the technology balance payments (OECD, 1990).

\footnotetext{
${ }^{2} \mathrm{~A}$ fifth revision is currently in progress.
} 
On the theoretical level, it is generally agreed that these internal and external enhancements of the Frascati Manual reflect the gradual replacement of the traditional linear concept of innovation with an interactive concept (as developed by Kline and Rosenberg, 1986). Thus R\&D is now envisaged as an activity that can take place at any stage of a given innovation process and not just at the beginning of the process. It can also take place independently of any clearly identified innovation process.

The general definition of R\&D advanced in the Frascati Manual currently reads as follows (OECD, 1993, paragraph 57):

'Research and experimental development (R\&D) comprise creative work undertaken on a systematic ${ }^{3}$ basis in order to increase the stock of knowledge 4 , including knowledge of man, culture and society, and the use of this stock of knowledge to devise new applications'.

This general definition is supplemented and clarified by the following definitions and conventions (hereinafter referred to as supplementary definitions) (OECD, 1993, paragraph 58):

' $R \& D$ is a term covering three activities: basic research, applied research and experimental development. Basic research is experimental or theoretical work undertaken primarily to acquire new knowledge of the underlying foundations of phenomena and observable facts, without any particular application or use in view. Applied research is also original investigation undertaken in order to acquire new knowledge. It is, however, directed primarily towards a specific practical aim or objective. Experimental development is systematic work, drawing on existing knowledge gained from research and or practical experience ${ }^{5}$, that is directed towards producing new materials, products and devices; to installing new processes, systems and services; or to improving substantially those already produced or installed'.

Three fundamental principles underlie these definitions:

\footnotetext{
${ }^{3}$ Our emphasis.

${ }^{4}$ Our emphasis.

${ }^{5}$ Our emphasis.
} 
- the notion of the production of knowledge;

- the systematic nature of this production;

- the criterion of an appreciable element of novelty in this knowledge.

We will not enter here into the complex debate on the nature of knowledge (its scope, its nature, its architecture and so on), although that debate has shed much light on the knowledge creation mechanisms in certain service activities, particularly knowledgeintensive services (Gallouj, 2002a). We will confine ourselves here to the question of the object of knowledge. The first two editions of the Frascati Manual focused solely on the natural sciences and engineering. They excluded the social sciences and the humanities. It was only from the third edition onwards (OECD, 1976) that they were explicitly included. From this point of view, the Frascati Manual's theoretical perspective can be said to be less technologist than that of the Oso Manual, which even in its latest edition (1997) focuses exclusively on technological product and process innovation.

The systematic nature of knowledge production means that R\&D is an intentional and organised activity. It excludes the 'mechanical' acquisition of knowledge through learning from practical experience. Nevertheless, excluding this 'by-product' of productive activities does not mean that $R \& D$ itself cannot be a locus for learning effects. Moreover, there is no reason why, at a given moment, these by-products cannot be the object of systematic work undertaken with a view to launching an experimental development activity. This is what is implied in the last phrase of the supplementary definition .

The fundamental element of this definition is the novelty of the knowledge created. The term 'new' is not explicitly used in the general definition, but it can be inferred from the fact that the 'stock of (human) knowledge' has to be increased. On the other hand, it is quite explicitly contained in the definitions of basic and applied research (cf. supplementary definition). Moreover, a whole paragraph is given over to the criterion of novelty (OECD, 1993, paragraph 79):

The basic criterion for distinguishing $R \& D$ from related activities is the presence in $R \& D$ of an appreciable element of novelty and the resolution of scientific and/or technological uncertainty, i.e. when the solution to a problem is not readily apparent to someone familiar with the basic stock of commonly used knowledge and techniques in the area concerned'. 
It will be noted, however, that the novelty criterion seems to be relaxed to some extent in the case of experimental development. Indeed, the reference to 'research and/or practical experience' in the supplementary definition opens up the possibility of listing as experimental development (and hence as R\&D) certain activities taking place in situations in which the systematic work is based not on new knowledge but on practical experience.

These definitions are not always easy to put into practice. In particular, the notion of novelty is a subjective one. Novelty can be produced (even in basic research) by combining existing knowledge, in accordance with a principle established in ancient philosophy. If a product can be new and therefore constitute an innovation without being based on $\mathrm{R} \& \mathrm{D}$, that is on the production of new knowledge, it is not always easy to establish a distinction between these two activities, particularly in services.

Thus the Manual proposes a set of different criteria and questions that may provide information that will help to distinguish $R \& D$ from related scientific, technological and industrial activities (OECD, 1993): the nature of the project objectives; the type of personnel allocated to the project; the methods used; the nature and source of the funding; the degree of generality of the conclusions or results obtained...

\section{What is a service, and what distinguishes it from a good?}

Undoubtedly the most satisfactory definition currently available to us is that advanced by Gadrey (1996), drawing on the work of Hill (1977), and denoted by the term 'service triangle'. In this definition, a service is made up of three elements, which form the corners of the triangle: the customer (A), the service provider (B) and the service medium (C). Thus a service is defined as a set of actions (processing operations) carried out by B for the benefit of A and often with the latter's participation (co-production). The actions carried out by A are intended to bring about a change of state in the medium $\mathrm{C}$, in other words to solve a problem concerning $\mathrm{C}$ without ending in the production of a good that would be able to circulate economically independently of $\mathrm{C}$.

Services may concern various mediums: tangible goods, codified information, knowledge and even individuals themselves (in their various aspects). Thus the provision of a service 
can be considered as a combination of various processing or problem-solving functions or operations relating to each of these mediums (cf. Table 1):

- 'tangible' operations or functions [M], which involve the 'processing' of tangible objects in some way (their transportation, transformation, maintenance, repair, etc.);

- 'informational' operations or functions [I], which involve the 'processing' of 'codified' information, that is producing, capturing, transporting it, etc.;

- contactual or relational service operations $[R]$, those whose principal medium is the customer himself and which consist of a direct service (one provided in contact with the customer);

- 'cognitive' or 'methodological' operations or functions $[\mathrm{K}]$, which involve the "processing" of knowledge through methods (codified routines, intangible technologies, etc.).

Each tertiary activity combines the four 'tangible', 'informational', 'methodological' and 'relational' functions in varying proportions that differ in both time and space.

Table I: A representation of a service and of its scientific and technological content

\begin{tabular}{|c|c|c|c|}
\hline Competences mobilised & $\begin{array}{l}\text { ("Internal " or " intermedi } \\
\text { and correspondin }\end{array}$ & $\begin{array}{l}\text { te ") functional breakdown } \\
\text { technical content }\end{array}$ & $\begin{array}{l}\text { (“" External ") use, final or } \\
\text { service characteristics or } \\
\text { functions }\end{array}$ \\
\hline \multirow{3}{*}{$\begin{array}{l}\text { Competences in the } \\
\text { technologies (use thereof) } \\
\text { or competences directly } \\
\text { mobilised [C] }\end{array}$} & $\begin{array}{l}\text { "Tangible" operations } \\
{[\mathrm{M}](+ \text { corresponding }} \\
\text { sciences and technologies })\end{array}$ & \multirow{3}{*}{$\begin{array}{l}\text { Contactual or relational } \\
\text { service operations }[\mathrm{R}](+ \\
\text { corresponding sciences } \\
\text { and technologies) }\end{array}$} & \multirow{3}{*}{$\begin{array}{l}\text { Service functions and } \\
\text { characteristics [Y] }(+ \\
\text { corresponding disciplines) }\end{array}$} \\
\hline & $\begin{array}{l}\text { "Informational" } \\
\text { operations [I] }(+ \\
\text { corresponding sciences } \\
\text { and technologies) }\end{array}$ & & \\
\hline & $\begin{array}{l}\text { "Methodological" } \\
\text { operations [K] }(+ \\
\text { corresponding sciences } \\
\text { and technologies })\end{array}$ & & \\
\hline
\end{tabular}

However, this representation of the product does not provide an adequate basis for tackling the question of innovation and R\&D in services. It has to be supplemented in various ways (cf. Gallouj, 2002b). 
The first amendment is in fact nothing more than a change of perspective. Given our objective here, the functional breakdown can also be envisaged as a scientific and technological breakdown that highlights, respectively:

- material-processing technologies (mechanics, robotics for example),

- information-processing technologies (computers and telecommunications, etc.),

- knowledge-processing technologies (intangible technologies, methods, etc.),

and, in each case, the corresponding scientific and technical disciplines.

The component $[\mathrm{R}]$ occupies a particular position in that the sciences and technologies used in processing relations or contactual services may borrow from each of the previous disciplines and indeed from others as well, particularly the social sciences and humanities.

The second amendment we suggest is more fundamental in that it involves enriching the preceding 'internal' functional breakdown and the corresponding technological and scientific content in two different ways:

- by taking into account, downstream, the 'external' service functions or characteristics obtained (utilities, use values), that is the qualitative characteristics;

- by introducing, upstream, the competences [C], whether they be competences in the various technologies deployed or competences used directly in producing the service utilities, characteristics or functions.

The value of these changes is that they make it possible to account for 'pure' service situations in which the service is provided directly by relying on the service providers' competences without any significant use of technologies. This particular service configuration can be denoted by the expression $\mathrm{C}(\mathrm{Y})$.

It is clear from these definitions that providing a service involves organising the response to a problem (generating new or improved service characteristics) by putting at the client's disposition a set of (human, technological, methodological and organisational) capacities and competences. It does not (or does not principally) involve the provision of a tangible good. 


\section{The general implications of the definition of services for the nature of R\&D}

When set alongside the guiding principle of the Frascati Manual (cf. Part 1), the definitions of services outlined in the previous section have a certain number of implications for the definition and nature of $R \& D$ in this type of activity. These implications relate in particular to the disciplinary fields mobilised, the novelty criterion and relations with the technologies. These implications are 'deduced' analytically. However, there are also empirical findings that serve to substantiate and illustrate them.

\subsection{The implications for the disciplinary fields}

The functional definition of a service, illustrated in Table 1, provides us with an heuristic tool for considering the implications of the nature of the service provided for the nature of the disciplinary fields (or types of R\&D) on which service providers draw. Four findings should be noted at the outset:

1) $R \& D$ in services can draw on a multiplicity of different disciplinary fields, and each field can be mobilised separately (specialised research projects).

2) Design and development or organisational engineering also occupies an important position.

3) Because of the very nature of services, $R \& D$ projects are often hybrid or composite affairs, combining research in a number of different disciplines corresponding to the various components of the service in question.

4) The social sciences and humanities (SSH) seem to occupy an important place in these various disciplinary fields.

Different disciplines, which may be the object of separate investigations

From a static point of view, every service activity is a combination, to varying degrees, of different types of operations or functions based on specific technologies and knowledge (Table 1). From a dynamic perspective, this concept suggests that, within any given service, there may be a variety of disciplines likely to identify problems and to create solutions (in other words, potential R\&D and innovation activity). 
Thus on the basis of a mechanical interpretation of the functional representation advanced in Table 1, the existence of activities that might aspire to the status of autonomous $R \& D$ can be envisaged in the following spheres:

1) the operations and sciences and technologies used to process material objects $(\mathrm{M}(\mathrm{Y}))$;

2) the operations and sciences and technologies used to process codified information $(\mathrm{I}(\mathrm{Y}))$;

3) knowledge-processing operations and sciences and technologies $(\mathrm{K}(\mathrm{Y}))$;

4) 'pure' service operations $(\mathrm{C}(\mathrm{Y}))$ and the corresponding scientific disciplines;

5) the operations and sciences and technologies used to process individuals and relations $(\mathrm{R}(\mathrm{Y})$ (in reality $\mathrm{MR}(\mathrm{Y}), \mathrm{IR}(\mathrm{Y}), \mathrm{KR}(\mathrm{Y})$ or $\mathrm{CR}(\mathrm{Y})$, depending on the particular relationship between the 'relational' function and the various technologies), as well as

6) the operations through which these various types of operations are combined or brought together (combinatory or architectural knowledge, engineering).

Thus each of these groups of operations or functions can be a locus for the development of new knowledge and thereby constitute, in a way, a separate type of R\&D.

The first two groups of operations $(\mathrm{M}(\mathrm{Y}))$ and $\mathrm{I}(\mathrm{Y}))$ involve the usual scientific and technological knowledge (scientific and technological R\&D, which are divided here into what might be called, to misuse the language somewhat, a 'material' form of R\&D given over to material-processing technologies and an 'informational' form of R\&D focused on information-processing technologies). 'Informational' R\&D (computer systems, software development), it should be noted, occupies a relatively important position in services. It is to this category that a large share of the $R \& D$ expenditure recorded in current surveys belongs.

The following two groups $(\mathrm{K}(\mathrm{Y}))$ and $\mathrm{C}(\mathrm{Y}))$ are the locus for what might be called a 'methodological' form of R\&D (focused on the intangible knowledge-processing technologies, that is methods) and a "service-oriented" R\&D (focused on the expression of new functionalities or service characteristics or significant improvements to existing functionalities or characteristics). These two types of $R \& D$ fall wholly within the province of the social sciences and humanities, particularly the organisational and behavioural sciences. They generate new knowledge about methods or new service characteristics; in this latter case, the knowledge produced is not the same as that 
generated by market or consumer research, which is more routine in nature, is capable only of limited generalisation and cannot aspire to the status of R\&D.

The last two groups $(\mathrm{R}(\mathrm{Y})$ and the combinatory operations) can be the object of two forms of $R \& D$ at the same time (technological $R \& D$ and non-technological $R \& D$ in the social sciences and humanities and in organisational engineering). In the case of the relational function $\mathrm{R}(\mathrm{Y})$, the $\mathrm{R} \& \mathrm{D}$ may involve traditional technological research (research into self-service technologies or into tangible or intangible customer loyalty technologies (cards, etc.)) as well as research in the sphere of psycho-sociology or into the organisation of the service relationship, for example. Thus interactivity, as a characteristic of service provision, or the interface, as the locus where that interactivity manifests itself, constitute one of the fundamental driving forces, one of the targets and one of the laboratories for research in service activities. However, whereas the service component $R(Y)$ constitutes a set of specific and clearly identifiable operations, the technologies and sciences associated with it are not specific, as we have already noted.

The relative importance of these various spheres of R\&D depends on the type of service activity in question, as well as on the firm's characteristics (particularly its structural characteristics). Although in theory every service activity can be broken down in accordance with the functional representation outlined above, the various 'spheres' obviously occupy different positions depending on the activity or firm concerned. In a large insurance company, for example, it is by no means unusual to be able to identify examples of R\&D projects whatever the particular component under consideration (including $\mathrm{M}(\mathrm{Y})$, as is shown by insurance companies' involvement in assistance services, which has given rise to work on home automation systems). Business strategy consultancy, on the other hand, seems unaffected by these material-processing operations and the corresponding research areas. Knowledge-intensive services present a particular problem as far as the definition of $R \& D$ is concerned. In terms of the functional representation, their main components by far are information and, above all, knowledge processing $(\mathrm{I}(\mathrm{Y})$ and $\mathrm{K}(\mathrm{Y})$ respectively) and the pure service component $\mathrm{C}(\mathrm{Y})$. Knowledge-intensive services are machines for processing information and knowledge with a view to creating (new) knowledge (Gallouj, 2002). The formal affinity with the definition of $R \& D$ is obvious but not sufficient to justify complete identification of the two activities. 


\section{Table 2: Examples of autonomous (or specialised) R-D projects}

(Source : survey conducted)

\begin{tabular}{|c|c|}
\hline Independent R-D sphere & Examples of R-D-I projects \\
\hline $\begin{array}{l}\text { R-D relating to the } \mathrm{M}(\mathrm{Y}) \\
\text { component ("material R-D") }\end{array}$ & $\begin{array}{l}\text { Automatic franking machines, postal sorting machines, cleaning chemistry, } \\
\text { specific cleaning cradles, new generation polishing machines, various vehicle- } \\
\text { processing technologies (in car supermarket set-up points), home automation } \\
\text { systems in assistance services. }\end{array}$ \\
\hline $\begin{array}{l}\text { R-D relating to the } \\
\text { component } \mathrm{I}(\mathrm{Y}) \\
\text { (" informational" } \mathrm{R}-\mathrm{D})\end{array}$ & $\begin{array}{l}\text { Automatic document scanning (Post office), electronic stamps, electronic keys, } \\
\text { expert scoring systems, queue management systems in amusement parks, mass } \\
\text { interactive video games (amusement parks), new generations of loudspeakers, } \\
\text { estimate standardisation software (cleaning), quality control software, advice } \\
\text { booths, self scanning, bank ATMs. }\end{array}$ \\
\hline $\begin{array}{l}\text { R-D relating to the } \mathrm{K}(\mathrm{Y}) \\
\text { component } \\
\text { (" methodological " } \mathrm{R}-\mathrm{D} \text { ) }\end{array}$ & $\begin{array}{l}\text { Design of an advance Euro zone indicator, development of innovative cleaning } \\
\text { protocols, methodological guide for the design of new training products, } \\
\text { numerous examples of consultants' methodologies. }\end{array}$ \\
\hline $\begin{array}{l}\text { R-D relating to the } \mathrm{C}(\mathrm{Y}) \\
\text { component ("service- } \\
\text { oriented" } \mathrm{R}-\mathrm{D} \text { ) }\end{array}$ & $\begin{array}{l}\text { Development of an original training product (training consultancy), studies of the } \\
\text { introduction of new functions into retailing: bagging at checkouts, crèches, home } \\
\text { deliveries, financial and insurance services, travel agencies, etc., risk prevention } \\
\text { measures (derived from research in SSH) in insurance industry, support } \\
\text { programmes for "technophobes" (derived from SSH work on the difficulties of } \\
\text { using NICTs), programmes to assist disadvantaged populations in using Euro } \\
\text { (based on research in psychology and the cognitive sciences). }\end{array}$ \\
\hline $\begin{array}{l}\text { Combinatory or architectural } \\
\text { R-D }\end{array}$ & $\begin{array}{l}\text { This form of R-D is seldom found as a autonomous aqctivity. Nevertheless, the } \\
\text { following example can be cited. Object information system (Post Office): this } \\
\text { mail tracing and tracking innovation is not revolutionary in terms of the } \\
\text { technologies deployed, namely hand-held scanners for delivery staff. On the other } \\
\text { hand, a sophisticated model of the organisation and of the mail processing process } \\
\text { had to be constructed in order to be able to ascertain the best points at which to } \\
\text { integrate these technologies. This was an extremely cumbersone and complex } \\
\text { intellectual exercice, which can be classified as design and development if not as } \\
\text { research. }\end{array}$ \\
\hline
\end{tabular}

The central role of design and development or organisational engineering

$R \& D$ in services frequently involves organisational engineering, and is sometimes an extremely complex undertaking. To engage in $R \& D$ of this kind is to design and develop 
a frequently original 'script' involving a number of actors, including the client himself, and to construct the corresponding multiplicity of variable 'backdrops'. In the case of manufactured goods, the tasks of assembly and integration relate to the material components; in services, on the other hand, the task is to assemble and integrate a number of animate or inanimate 'objects' into a complex system or organisation, what in the sociology of innovation is known as a 'hybrid collective' (Callon, 1991). As soon as the material world, with its reassuring reference points, is left behind, the whole undertaking can become more difficult; new and complex questions can be raised, the answers to which may also be new and previously unthought of and which may therefore increase the stock of available knowledge'. Obviously, such exercises in design and development or organisational engineering are closely related to the combinatory form of $R \& D$ mentioned above, which indeed is an essential dimension of these activities.

\section{Composite projects}

R\&D can be envisaged 'autonomously', that is as a specialist activity within the disciplinary field of a particular type of operation. Usually, however, the various operations listed above, and consequently the various problems that have to be solved, are closely linked. Thus $R \& D$, as a problem-solving activity, is in many cases a highly composite activity that combines technical, organisational, social and economic problemsolving activities relating to the components $\mathrm{M}(\mathrm{Y}), \mathrm{I}(\mathrm{Y}), \mathrm{C}(\mathrm{Y})$ and $\mathrm{R}(\mathrm{Y})$ and to architectural problems (cf. Table 4). In each of these cases, new solutions are devised, with new technical, organisational (including architectural), social and economic knowledge being generated. The composite nature of $\mathrm{R} \& \mathrm{D}$ projects makes it much more complicated to identify and measure them. In essence, only the technological R\&D component is currently taken into account in national and international surveys.

Table 3 : Examples of composite R-D projects (Source : survey conducted)

\begin{tabular}{|l|l|}
\hline \multicolumn{1}{|c|}{ Composites R-D projects } & \multicolumn{1}{|c|}{ The various spheres of R-D concerned } \\
\hline $\begin{array}{l}\text { Dependence insurance (product } \\
\text { innovation) }\end{array}$ & $\begin{array}{l}\text { Theoretical (conceptual) study of the definition of the notion of } \\
\text { dependence, followed by the formulation of formal specifications, actuarial } \\
\text { study, IT study. }\end{array}$ \\
\hline $\begin{array}{l}\text { Creation of an establishment } \\
\text { specialising in mail order saving } \\
\text { and investment products }\end{array}$ & New products, new processes, new organisation, Combinatory R-D. \\
\hline $\begin{array}{l}\text { Establishment of a postal deposit } \\
\text { bank }\end{array}$ & $\begin{array}{l}\text { Development of new banking know-how and of know-how relating to call } \\
\text { centres, complete overhaul of computer system, combinatory R-D. }\end{array}$ \\
\hline $\begin{array}{l}\text { New store concept (chain of car } \\
\text { supermarkets) }\end{array}$ & $\begin{array}{l}\text { Theoretical study of the historical evolution of the concept, repositioning of } \\
\text { supply in the laboratory (conceptualisation of the reorganised store), } \\
\text { construction of phantom store and then of pilot store, combinatory R-D. }\end{array}$ \\
\hline
\end{tabular}




\begin{tabular}{|l|l|}
\hline $\begin{array}{l}\text { New hotel format or concept } \\
\text { considered revolutionary in the } \\
\text { trade }\end{array}$ & $\begin{array}{l}\text { Definition of the concept: theoretical model specifying the functional, } \\
\text { physical, technical and economic dimensions, value analysis and research } \\
\text { focusing on the reduction of production costs, search for industrial } \\
\text { construction procedures. }\end{array}$ \\
\hline Computer system cleaning service & $\begin{array}{l}\text { Construction of new functionalities, new occupational identities, new types } \\
\text { of customer relations and new technical systems. Combinatory R-D. }\end{array}$ \\
\hline
\end{tabular}

The importance of social sciences and humanities

The issue of measuring R-D in service industries shouldn't be confused with that of measuring R-D in SSH. Frascati Manual explicitly introduced SSH in its definition of RD. However, there are very few, if any, surveys carried out by national statistical institutions that take advantage of this extended definition. It is assumed that firms' involvement in knowledge creation in SSH is negligible. For example, the statistical reports compiled by the French Department of Research and Technology clearly indicate that 'R\&D work in the sphere of SSH is not included in the statistics because of the insignificant role it plays in industrial research and the methodological difficulties specific to this area'. However, we will see that, in services more than elsewhere, such activity is by no means insignificant.

The knowledge generated by and R\&D in the social sciences and the humanities are much more important in services than in manufacturing industry. In some service activities, for example, despite the development of a (visible and spectacular) technical medium, it is by no means unusual for the real creativity (the creation of new knowledge) to manifest itself through the development of a 'social dimension' involving the systematic creation of new and original social relations and of new modes of organisation and behaviour.

It is important to note that $R \& D$ in the social sciences and humanities is not confined to basic research. In SSH as well, firms are increasingly tending to prioritise applied research, or even experimental development. The distinction is not always an easy one to make. Table 4 provides a few illustrations. It should also be noted that in some high-level occupations (knowledge-intensive services, particularly consultancy), research (even when it has no direct application: development of new services, etc.) is an essential communication and marketing instrument. Thus, for example, some lawyers in large law firms (when they are not academics themselves) can boast lists of publications worthy of university researchers. 
Table 4 : From basic research to experimental development in the social sciences and humanities (Source : survey conducted)

\begin{tabular}{|c|c|c|c|}
\hline $\begin{array}{l}\text { Service } \\
\text { activity }\end{array}$ & Basic research & Applied research & Experimental development \\
\hline Post Office & $\begin{array}{l}\text { Theoretical studies of the } \\
\text { limits of the concept of } \\
\text { productivity in services }\end{array}$ & $\begin{array}{l}\text { Application to postal services and } \\
\text { critique of the evaluation tools } \\
\text { used in the Post Office }\end{array}$ & $\begin{array}{l}\text { Construction of new performance } \\
\text { evaluation tools }\end{array}$ \\
\hline $\begin{array}{l}\text { Insurance } \\
\text { company }\end{array}$ & $\begin{array}{l}\text { Sociological research into } \\
\text { perceptions of the risk } \\
\text { associated with using the } \\
\text { roads. }\end{array}$ & $\begin{array}{l}\text { Application to a population of drug } \\
\text { users. }\end{array}$ & $\begin{array}{l}\text { Development of preventive tools } \\
\text { (seminars, video cassette, } \\
\text { information brochures...) }\end{array}$ \\
\hline Bank & $\begin{array}{l}\text { Theoretical enquiries on } \\
\text { the general theme of the } \\
\text { Euro zone and an } \\
\text { "integrated" approach to } \\
\text { the Euro zone. }\end{array}$ & $\begin{array}{l}\text { Addressing of particular problems } \\
\text { within this general theme : tax } \\
\text { harmonisation, employment } \\
\text { problems, social problems... }\end{array}$ & $\begin{array}{l}\text { Application to the design of an } \\
\text { " advanced Euro zone indicator" }\end{array}$ \\
\hline
\end{tabular}

\subsection{The implications for the novelty criterion}

Some of the specificities of services encourage investigation of the novelty criterion as applied to the definition of R\&D (without, for all that, calling it into question).

Firstly, in the case of services, the technical criterion of interactivity tends to introduce systematic elements of novelty, which may constitute some of the ingredients of R\&D activity. $R \& D$ does indeed produce novelty, but it also feeds on it, in that it is often the unprecedented nature of a problem that is the source of new knowledge. This difficulty is all the more pronounced in the case of interactive services, and even more so when it involves the processing of knowledge (consultancy, for example).

Secondly, without engaging in philosophical discussions on the modalities of knowledge creation, it is generally recognised that new knowledge can emerge from the combination of existing knowledge. Without abandoning the novelty criterion, it would seem that novelty can be produced through different channels. In services (although this is also true of R\&D in new computer technologies and biotechnologies), R\&D and innovation have a strong architectural dimension.

Thirdly, although it is often difficult, it is necessary to distinguish novelty from what is generally called (marketing) packaging. Market services obviously are more concerned 
by this distinction than public services which are not or less supposed to be managed through marketing techniques.

\subsection{The implications for the relationship to technologies}

Since the provision of a service is synonymous with making available resources (including technologies), it can readily be understood that services have a different relationship to technology from that of goods. Indeed, the technology is not consubstantial with the service but is external to the service characteristics provided. If absolutely necessary, a service can even 'dispense with it', which to some extent deprives these activities of one of the main objects or usual mediums for R\&D activity and explains why such activity is underestimated. The particular position of technologies means that the traditional distinction between product and process innovation, as well as that suggested in the Frascati Manual between the R\&D associated with product innovation and that associated with process innovation, are difficult to make.

Moreover, a distinction has to be made between back-office and front-office technologies. It would seem that service firms are (generally, except when the technology in question is highly specific) more involved in $R \& D$ relating to front-office technologies. This can be explained by the fact that front-office technologies are more specific because they are dependent on the particular nature of the interaction with the customer.

\section{The implications for some of the problems on the borderline between $R \& D$ activities and other industrial activities}

Chapter 2 of the Frascati Manual examines the list of activities close to R\&D that might give rise to problems on the borderline between $R \& D$ and other industrial activities and suggests some criteria that might be used to differentiate them from R\&D proper. Certain activities may indeed be properly classified as R\&D or distinguished from it, depending on the circumstances. Some that merit particular attention, or even a shifting of the borderline as far as services are concerned, are examined here. They are the following:

- the construction of a prototype

- the construction and operation of a pilot plant

- design work 
- tooling-up and industrial engineering

- experimental development and manufacturing start-up.

The main problem raised by these activities is that, in certain cases, they can be applied without difficulty, while in others they prove unsuitable or reveal overlaps between categories, which reduce their validity. These instance of unsuitability and overlap can be explained by the particular nature of services. It is important to flag them up in order to avoid underestimating the various activities concerned.

\subsection{The notions of prototype, pilot plant and design work}

These three notions deserve to be examined together, since it is our view that there can, in certain cases, be particular relations between them in services. The Fracati Manual defines them and establishes the boundaries between them in the following terms:

- 'A prototype is an original model constructed to include all the technical characteristics and performances of the new product' (OECD, 1993, paragraph 115).

- 'The construction and operation of a pilot plant is a part of $R \& D$ as long as the principal purposes are to obtain experience and to compile engineering and other data to be used in: evaluating hypotheses; writing new product formulae; establishing new finished product specifications; designing special equipment and structures required by a new process; preparing operating instructions or manuals on the process » (OECD, 1993, paragraph 117).

- 'Design is an essential part of the innovation process. It covers plans and drawings aimed at defining procedures; technical specifications; and operational features necessary to the conception, development, manufacturing and marketing of new products and processes. It may be part of the initial conception of the product or process, i.e. research and experimental development, but it may also be connected to tooling-up, industrial engineering, manufacturing start-up, and marketing of new products' (OECD, 1993, paragraph 21).

The Frascati Manual also considers that "the vast bulk of design work in an industrial area is geared towards production processes and as such is not classified as R\&D. There are, however, some elements of design work which should be included as R\&D. These 
include plans and drawings aimed at defining procedures, technical specifications and operational features necessary to the conception, development and manufacturing of new products and processes' (OECD, 1993, paragraph 125).

It is clear that, in some cases, the preceding definitions apply perfectly to services.

1) The Frascati Manual's definition of a prototype clearly refers to a material artefact. The example provided is quite explicit in this respect: it is a pump for corrosive liquids. As we have already noted, a definition of this kind does not of course pose any problems in the case of traditional technological $R \& D$, which is absolutely the same in manufacturing and service firms.

2) The objectives of a pilot plant, as expressed in the Frascati Manual's definition, apply perfectly to the various types of pilot installations encountered in service activities: phantom store, pilot hypermarket, life-size hotel room (cf. Table 5).

3) Similarly, the definition of 'design work' seems to be applicable to many service activities. Drawings and plans defining procedures, technical specifications and operational characteristics are indeed produced.

Table 5 : Examples of pilot installations in services (Source : survey conducted)

\begin{tabular}{|l|l|}
\hline \multicolumn{1}{|c|}{ Type of pilot installation } & \multicolumn{1}{|c|}{ Description } \\
\hline $\begin{array}{l}\text { Pilot hypermarket } \\
\text { (Carrefour) }\end{array}$ & $\begin{array}{l}\text { Exact reproduction of a typical store over an area of } 4500 \mathrm{~m}^{2 .} \mathrm{A} \\
\text { genuine life-size laboratory, the purpose of which is to test all the } \\
\text { firm's innovation projects : validation of display equipment, testing } \\
\text { of products places and " consumers worlds ", etc. }\end{array}$ \\
\hline Phantom store (Norauto) & $\begin{array}{l}1000 \mathrm{~m}^{2 .} \text { warehouse equipment like a real car supermarket. It has } \\
\text { been used to test the new store concept: fittings, equipment, } \\
\text { accessories used to create atmosphere, etc. }\end{array}$ \\
\hline $\begin{array}{l}\text { Life-size hotel room } \\
\text { (Suitehotel, Accor) }\end{array}$ & $\begin{array}{l}\text { Life-size model of a room in a Suitehotel, a new concept in hotels. } \\
\text { The purpose of the model was to test the concept : change the fitted } \\
\text { carpet, alter the size of the washbasin, etc. }\end{array}$ \\
\hline
\end{tabular}

However, comparison of the Frascati Manual definitions with the specific characteristics of services and our survey findings leads us to make a certain number of observations and qualifications. 
1) As far as pilot installations are concerned, despite the apparent match between the official definition and the examples cited, surveys of R\&D in services seldom manage to record them as such. The explanation for this paradox lies undoubtedly in the continued tendancy to consider pilot installations and pilot plants as synonymous.

2) Design work is an essential component of $R \& D$ and innovation in services. If, according to the Frascati Manual, the bulk of such activity in manufacturing industry should not be classified as $R \& D$, it is likely that the opposite is the case in services. It may amount to nothing more than a (relatively simple) 'plan' or equivalent representation : this applies, for example, to the technical and functional specifications of a financial product and to the general conditions for a new hotel formula that include the functional, technical, organisational, architectural and economic specifications. Usually, however, design or conception work is more sophisticated and more dynamic, in that it involves the construction of a scenario (and not just of an inert plan), a script or a life-size representation. This is the category in which the sophisticated representations of services known in the literature by the terms 'blueprint' or 'flowchart' (cf. Shostack, 1984; Kingman-Brundage, 1992) undoubtedly belong. Thus the distinguishing criterion proposed in the Frascati Manual, according to which design work geared towards production processes should be excluded from $R \& D$, loses its operational character. It is difficult to distinguish between activities (plans and drawings, etc.) required for the initial conception of the product or process, which would fall within the scope of $R \& D$, and those required for manufacturing start-up or marketing, which would not be classified as $R \& D$. In services, these two groups of activity are often inextricably linked.

3) As far as prototypes are concerned, the reference to a material artefact seems to preclude the existence of this type of activity in many R\&D projects. Indeed, while it is clear what the prototype for a bank ATM is, what is the prototype for a financial product, holiday package, etc.?

4) The preceding observation raises a more fundamental problem, namely that of the boundary between the notions of prototype, pilot installation and design work. In services, it is by no means uncommon to find that what is called a prototype is in fact a paper prototype, that is the outcome of 'design work'. The difficulty arises out of the fact that, in many service situations, the prototype can work only in the presence of the client, that is when it is introduced into the market. In many cases, moreover, the prototype and 
the pilot installation are indissociable. This is very obviously a consequence of the nature of the product in services, which is not an artefact but an act or a series of processing operations in which it is difficult to separate out the product, the process and the organisation.

5) The ambiguities inherent in and the points of overlap between the notions of prototype, pilot installation and design work have repercussions on the notion of test. In services, the borderline between 'technical' tests and 'economic' tests is sometimes tenuous. Indeed, a product has to be introduced on to the market in order to verify its operating modalities. This is due to the particular relationship that exists between the service provider and the technology. The technology, when it exists, is 'external' to the service and not consubstantial with it, as it is in the case of goods. It is the service providers' competences, together with the clients', that replace a good's technical characteristics and embody, in a way, the service characteristics provided. In many cases, therefore, the test is not a test carried out 'under laboratory conditions' or 'away from the market' since it concerns the organisation of individuals, including the customer, relative to a 'product' that is not static but is defined as a set of acts. This is a 'real-life' test.

\subsection{Industrial engineering}

This activity involves the assembling of components whose technologies are known. It is classified as R\&D only if the integration process is not strictly mechanical, in other words if it poses problems whose resolution requires $R \& D$. In most cases, therefore, industrial engineering is considered 'to be part of the production process' and not as R\&D (cf. OECD, 1993, paragraphs 127 and 130).

This activity has strong industrial connotations, as its name indicates. Now as we noted in section 3.3. above, services are also the locus for significant engineering activity. Industrial engineering certainly exists in services, since technical systems are produced, the various components of which have to be assembled and integrated. However, the main focus of engineering activity in services lies elsewhere, in a particular form of engineering denoted by the term service or organisational engineering, which involves integrating or assembling different components, not necessarily tangible ones, in accordance with the representation depicted in Table 1. This new form of engineering, unlike the previous one, cannot be excluded from R\&D on the grounds that it is part of 
the production process, since production, process and organisation are often very difficult to separate out.

\subsection{Experimental and development pre-production}

It is often difficult to define precisely the border between experimental development and pre-production development. The latter involves in particular 'producing user demonstration models and testing, and production that is applicable to all industrial situations' (OECD, 1993, paragraph 112). In order to make it possible to locate the cutoff point between experimental and pre-production development, the Frascati Manual refers to a basic rule proposed by the US National Science Foundation (NSF) (OECD, 1993, paragraph 112):

'If the primary objective is to make further technical improvements on the product or process, then the work comes within the definition of R\&D. If, on the other hand, the product, process or approach is substantially set and the primary objective is to develop markets, to do preproduction planning, or to get a production or control system working smoothly, then the work is no longer R\&D'.

This NSF definition adopted by the Frascati Manual cannot always be easily applied to services. Indeed, its high degree of interactivity and intangibility means that the product of a service activity is seldom "set" or "fixed" in the same way that a good is. True, efforts to fix the product can be made, and it could be said that in many cases the objective of R\&D is to do precisely that. Conversely, in some cases (such as insurance), the product is definitively fixed when it is launched. Indeed, new financial and insurance products are characterised by a ratchet effect: companies have to continue to manage

policies for several decades, even if those products prove to be a failure and are withdrawn from the market.

\section{The implications for the modes of $R \& D$ organisation}

In the same way as previously, certain implications for the organisation of R\&D can be inferred from an examination of the definitions of services. These implications concern the nature of the entities or actors engaged in $R \& D$, and in particular the definition of a researcher. 
The interactive nature of services has several consequences for the organisation of R-D-I. After all, this characteristic seems incompatible with a linear model of R-D-I organisation (based on the existence of a specialist R\&D department). On the other hand, it is more consistent with an interactive model, based on R-D-I entities operating in multiple locations, the existence of temporary project groups and client participation.

Although they are rare, specialist departments do exist in certain cases. Table 6 provides some examples. Be that as it may be, these departments are never the only or even the main source of $R \& D$ in service firms.

Table 6 : Examples of formally constituted R-D-I departments in services (Source : own survey)

\begin{tabular}{|c|c|}
\hline $\begin{array}{l}\text { Name of specialist R-D-I } \\
\text { department }\end{array}$ & Description \\
\hline $\begin{array}{l}\text { Research Group (in economic and } \\
\text { social sciences) (Post Office) }\end{array}$ & $\begin{array}{l}\text { Group of } 3 \text { people with contacts in all departments. Draws up a research } \\
\text { programme and subcontracts research to universities. Manages CIFRE } \\
\text { university/industry studentships in the social sciences and humanities. } \\
\text { Seminars, conferences, publications, PhD examining boards, etc. }\end{array}$ \\
\hline $\begin{array}{l}\text { Post Office Technical Research } \\
\text { Department }\end{array}$ & $\begin{array}{l}230 \text { people. As well as technological R\&D, this department is becoming } \\
\text { increasingly involved in the provision of technical expertise, in product } \\
\text { evaluation and company certification. Seminars, conferences, } \\
\text { publications, PhD examining boards, etc. }\end{array}$ \\
\hline $\begin{array}{l}\text { Research and } \\
\text { department (bank) }\end{array}$ & $\begin{array}{l}18 \text { people, graduates of elite engineering and business schools. Apart } \\
\text { from its basic research mission, this department also provides expertise, } \\
\text { conducts surveys and studies and provides consultancy services. } \\
\text { Seminars, conferences, PhD examining boards. }\end{array}$ \\
\hline $\begin{array}{lll}\text { New } & \text { technologies } & \text { department } \\
\text { (bank) }\end{array}$ & $\begin{array}{l}40 \text { people, an } \mathrm{R} \& \mathrm{D} \text { team in financial mathematics, an } \mathrm{R} \& \mathrm{D} \text { team in } \\
\text { statistics and a technology monitoring team specialising in new IT tools. }\end{array}$ \\
\hline $\begin{array}{l}\text { Research Department (training } \\
\text { consultancy) }\end{array}$ & $\begin{array}{l}4 \text { people. The director has a PhD in SSH. Development and } \\
\text { experimentation in new teaching technologies. Establishment of } \\
\text { partnership with university teachers/researchers. Seminars, conferences, } \\
\text { publications. }\end{array}$ \\
\hline
\end{tabular}

All in all, 'marginal R\&D' (that is, 'R\&D carried out informally in units for which it is not the main activity') can be said to be more common in services than 'core R\&D' (that is R\&D 'carried out in formal R\&D departments'), in accordance with the distinction laid down in the Frascati Manual (OECD, 1993, paragraph 392, p. 105). In other words, R\&D is carried out in numerous places where it is not the main activity, and full-time researchers are few in number. In services, the sum of secondary R\&D is often greater than primary $R \& D$. 
Thus those engaged in research may come from different departments: marketing, IT, legal affairs, and so on. They may be managers from any function within the company. There are certainly engineers in this population, but there are also legal experts, economists, sociologists, psychologists, management experts, architects, etc. The profiles of these researchers encompass the whole spectrum of academic disciplines, whether in the natural sciences or in the social sciences and humanities.

It should be noted that the Frascati Manual's definition of a 'researcher' does not exclude such profiles:

'Researchers are professionals ${ }^{6}$ engaged in the conception or creation of new knowledge, products, processes, methods, and systems, and in the management of the projects concerned' (OECD, 1993, paragraph 311).

The term 'professional' does indeed encompass specialists in both the natural sciences and in the social sciences and humanities. Specialists in the social sciences and humanities can function both as genuine researchers ('engaged in the conception or creation of new knowledge') and as research project managers. In our view, this general definition of a researcher is, paradoxically, broader and more satisfying than that of research. It quite explicitly uses the term 'conception' (and not just the term creation), to which we attach particular importance in services (cf. section 3). Furthermore, it introduces the terms 'methods' and 'systems', which are also important in services.

\section{A new definition of R\&D for goods and for services}

Our basic hypothesis is that it is not necessary to set goods and services against each other when it comes to the definition of $R \& D$ and that there is no need, therefore, to offer a different definition for each of these activities. It is sufficient, within an integrative approach, to make marginal changes to the current definition.

\subsection{Why a single definition for goods and services?}

\footnotetext{
${ }^{6}$ Our emphasis.
} 
The basic argument in favour of a single definition of R\&D that would apply to both goods and services is that it would recognise that, for some years now, there has been a certain degree of convergence between these two types of activities.

In many industrial and agricultural activities, the service dimension and the service relationship have been growing in importance. This change in the nature of the 'product' manifests itself in various (closely linked) ways that we can do no more than list here:

- the value of many goods stems principally from service functions, with manufacturing operations tending to decline. This applies not only to high-tech products but also to seemingly more anodyne products, for example potatoes (Nahon and Nefussi, 2002);

- services 'around the product' are becoming increasingly important;

- some firms, both in high-tech areas and in more traditional spheres, that have been known as manufacturing companies are now in fact genuine service companies, the most frequently cited examples being IBM and Benetton. At a more conceptual level, it can be said that many manufacturing companies no longer define themselves in the same way as companies producing goods but rather like companies creating solutions, service characteristics. Thus a car manufacturer sees itself as a provider of services in kilometres; - many firms do not sell a good or a service but a system or a 'package' of closely linked goods and services.

On the other hand, there is a phenomenon that is probably longer established and that is sometimes described as the industrialisation of services; depending on the case in question, it denotes processes of standardisation, the introduction of technical systems, etc.

These two observations have two consequences for the definition and evaluation of R\&D:

- The strict definition of R\&D (the one in the Frascati Manual) is useful for apprehending services in terms of their industrialisation. It is therefore highly likely that an analysis of medium or long-term time series would reveal an increase in the R\&D effort (in the traditional sense) in services.

- The amended definition could help to highlight some 'atypical' R\&D efforts in manufacturing firms (relating to the increasingly important service aspect).

\subsection{What amendments should be proposed?}


In order to reflect to some extent the specificity of services, a new definition of R\&D should take account of the following elements.

1) As far as the 'R' component is concerned, our investigations confirm that traditional (basic or applied) research is indeed carried out in services. They also show that service firms carry out research in the social sciences and humanities (again both basic and applied). However, this research in the social sciences and humanities occupies an essential place in services. The current definition of $R \& D$ does not exclude this area of research; as it stands, however, it cannot be used to break the habit, inherited from the industrialist tradition, of considering such research as a very marginal activity that deals with less important economic and strategic issues.

2) Within the social sciences and humanities, one area in particular occupies an extremely important place, particularly as far as services are concerned. This is research into productive organisations and the behaviour of economic agents, particularly customers. Such research deserves to be explicitly included in the general definition. Indeed, research in these areas (non-technological R\&D) has given rise to many innovations in services: new modes of service provision and new services, as well as new types of relations (new ways of organising relations) with other partners, such as suppliers, for example, etc.

3) There is considerable activity in services in the $D$ component of the R\&D process. An enormous amount of experimental development is carried out, which it would perhaps be more accurate to call design and development (D\&D), particularly since the $D \& D$ process can take place without any prior $\mathrm{R}$. This is the sphere of service or organisational engineering, where the focus is on the production of scripts, plans, models and blueprints and the arranging of animate and 'inanimate' objects. This engineering or D\&D involves putting into practice, as it were, the findings of SSH research into organisations and the behaviour of agents.

4) R\&D projects in services are seldom specialised projects, that is they do not often fall within the scope of a single type of discipline. They are frequently composite projects, in which several families of disciplines are inextricably linked (technological $R \& D$ relating to hardware or software and non-technological R\&D in the social sciences and 
humanities and organisational engineering). Clearly, a set of analytical or survey tools that captures only technological $R \& D$ will underestimate the $R \& D$ effort in service firms.

A general definition that took account of these remarks could be formulated as follows (the proposed amendments are in bold):

'Research, design and experimental development (R-D-D) comprise creative work undertaken on a systematic basis in order to increase the stock of knowledge, including knowledge of man, culture and society (particularly knowledge of the behaviour of economic agents and that of productive organisations), and the use of this stock of this knowledge to devise new applications (whether they involve goods, services, processes, methods or organisations).'

This new definition does not modify the old one in any revolutionary way. It confines itself to marginal amendments, particularly by introducing the term conception, to take account of an activity that occupies a particular position in services, by stressing knowledge of behaviour and organisations and by making it possible to take account of organisational engineering. In other words, this new definition confines itself to making explicit certain elements that have hitherto remained implicit. This clarification is one of the basic preconditions for breaking out of industrialist inertia. Thus these minor modifications may potentially give rise to major changes in the identification and measurement of R\&D in services.

Whether it is conducted in manufacturing or service firms, research in the social sciences and humanities, the importance of which has already been noted, raises particular problems of identification and measurement. It is often difficult to distinguish research proper from routine, factual studies whose findings cannot be generalised. The answers to the following questions may provide some starting points for differentiating between the two. Could the study in question be published in a peer-reviewed academic journal? Does the department in question call on specialist (academic) researchers and to what extent have they contributed to the study? What is the background of the head or members of the unit likely to carry out such work? Our empirical study shows that the directors of economic research departments in the banking and insurance industries are sometimes recognised academics, who continue to publish in academic journals, and that some lawyers are eminent academics. Moreover, some large service companies have units dedicated to research in the social sciences and humanities (the Post Office's 
Research Group, foundations associated with certain insurance companies, etc.) that contribute to basic and applied research and even to experimental development.

More generally, whatever the area of $\mathrm{R} \& \mathrm{D}$ under consideration, there are certain criteria that may provide some leads when it comes to determining whether or not R\&D activity exists:

- patent applications;

- the presence of prototypes, pilot installations or sophisticated products of design studies (flowcharts, blueprints);

- publications in peer-reviewed journals (traditional scientific and technical journals and social science and humanities journals);

- publication in peer-reviewed journals 'feasible' but not actually achieved for various reasons;

- membership of journal editorial or academic boards;

- publication of books by 'academic' publishers;

- series editors for 'academic' publishers;

- organisation of academic seminars or conferences;

- participation in such seminars;

- presence of doctoral students (particularly those on joint university/industry programmes, such as CIFRE in France and CASE in the UK, whatever the discipline);

- membership of PhD. examining boards;

- membership of honorary degree committees;

- the background of certain managers and executives (former or current academics)

- the existence of partnerships with universities;

- links with research laboratories;

- the establishment of foundations dedicated to research.

Most of these indicators have obvious limits. To cite only one example, it is not always easy to identify the genuine peer-reviewed journals. Thus they must be crosschecked against each other and used to form clusters of indicators.

The composite nature of $\mathrm{R} \& \mathrm{D}$ projects leads automatically to the involvement of different researchers: researchers of the traditional kind, researchers in the social sciences and humanities and researchers in organisational engineering (or 'designers'/‘developers'). However, there is no reason to amend the Frascati Manual's 
definition of a researcher, since the proposed new definition of $R \& D$ and the remarks set out above are absolutely consistent with the Frascati Manual's definition of a researcher. This new definition of R\&D can be interpreted as an attempt to re-establish some degree of consistency between the definition of research and that of a researcher (which is more satisfactory, in our view, for several reasons). Nevertheless, some minor modifications (indicated in bold) could be suggested, not in order to effect any substantive change but simply for pedagogical reasons (with a view to breaking out of the inertia of the industrialist perspective):

'Researchers are professionals in the natural sciences or the social sciences and humanities (including various categories of designers and 'developers') engaged in the conception or creation of new knowledge, products, processes, services, methods, and systems, and in the management of the projects concerned' (OECD, 1993, paragraph $311)$.

\section{Conclusion}

Services are constantly challenging economic theory and our evaluation systems. Productivity in services is no lower than in other sectors of the economy, and there is no less innovation. It is our theoretical concepts and the measurement systems arising out of them that are unsuitable. Similarly, it is likely that R\&D is underestimated and that, here too, it is the inertia of our industrialist apparatuses that is responsible.

We have not sought in this paper to call into question the definition of R\&D in any fundamental way. It was not our aim to advance an excessively extended definition that would take account of all activities in firms leading to the creation of new knowledge, since any such concept of R\&D would be devoid of all theoretical and operational value.

The proposed amendments do not fundamentally alter the definition and do not pit goods and services against each other. They are intended merely to induce a certain 'psychological shock' with the aim of reducing the influence of the industrialist and technologist inertia, which continues, despite all efforts to the contrary, to shape more or less subconsciously surveys on $\mathrm{R} \& \mathrm{D}$ and to contribute to the underestimation of the $\mathrm{R} \& \mathrm{D}$ carried out in service firms. In order to illustrate the marginal nature of the proposed amendments, we could say that our aim is to make the Frascati Manual's definition of research more compatible with that of a researcher. 
Such a marginal revision of our definitions would lead to a re-evaluation of the R\&D carried out within service firms. Some of the components of such R\&D have already been clearly identified and measured, namely technological R\&D in the traditional sense. Others are hardly ever evaluated, although the Frascati Manual's definition is not to blame here: we refer to research in the social sciences and humanities, which is considered negligible in terms of both quantity and significance. Other types of creative activities (which inextricably combine products, process and organisation) largely elude attempts at measurement: we refer here to what it has been agreed to call conception and development, or organisational or service engineering.

The proposed revision is not intended simply to gain better knowledge of or 'recognition' for R\&D in services. It can also help to improve our understanding and evaluation of R\&D in industrial firms themselves, in which a certain number of service characteristics are becoming increasingly evident in products, behaviour and modes of organisation. This improved knowledge has obvious consequences for public policies in support of R\&D.

\section{Bibliography}

W Baumol (2002), "Services as leaders and the leader of services », in J Gadrey, F Gallouj (eds), Productivity, Innovation and Knowledge in services (Edward Elgar, Cheltenham UK, Northampton USA).

M Callon (1991), "Réseaux technico-économiques et irréversibilité" in R Boyer, B Chavance, $\mathrm{O}$ Godard (eds), les figures de l'irréversibilité en économie, (La Découverte, Paris).

J Gadrey (1996), L'économie des services, (La Découverte, Paris).

F Gallouj (2002a), Innovation in the service Economy: the new wealth of nations (Edward Elgar, Cheltenham UK, Northampton USA).

F Gallouj (2002b), «Knowledge intensive business services : processors of knowledge and producers of innovation », in J Gadrey, F Gallouj (eds), Productivity, Innovation and Knowledge in services (Edward Elgar, Cheltenham UK, Northampton USA).

P Hill (1977), «On goods and services», The Review of Income and Wealth, 2, december, pages 315-338. 
J Kingman-Brundage (1992), «The ABCs of Service System Blueprinting », in C Lovelock (ed) Managing services, (Prentice-Hall International editions, Englewood Cliffs).

S Kline, N Rosenberg (1986), «An overview of innovation » in R Landau ; N Rosenberg (eds) The positive sum strategy : harnessing technology for economic growth, (National Academy Press, Washington D.C).

D Nahon, J Nefussi (2002), «Les services au cœur de l'innovation dans la production agricole : 1'exemple de la pomme de terre », in F Djellal, F Gallouj (eds), Nouvelle économie de service et innovation, (L'harmattan, Paris).

OECD (1976), Proposed Standard Practice for Surveys of Research and Experimental Development : Frascati Manual (OECD, Paris, third edition).

OECD (1990), Proposed Standard Method of Compiling and Interpreting Technology Balance of Payments Data : TBP Manual (OECD, Paris).

OECD (1993), Proposed Standard Practice for Surveys of Research and Experimental Development : Frascati Manual (OECD, Paris, fifth edition).

OECD (1994), Using Patent Data as Science and Technology Indicators : Patent Manual (OECD, Paris).

OECD (1995), The measurement of Human Resources Devoted to S\&T: Canberra Manual (OECD, Paris).

OECD (1997), Proposed Guidelines for Collecting and Interpreting Technological Innovation Data : Oslo Manual (OECD, Paris, second edition).

Shostack G.L. (1984), « Service Design in the Operating Environment », in W R George, C E Marshall (eds), Developing New Services, (American Marketing Association, Proceedings Series, Chicago). 